EMBRYARIDDLE
Aeronautical University

SCHOLARLY COMMONS

\section{International Journal of Aviation,} Aeronautics, and Aerospace

\title{
The Detrimental Effect of Rainfall on Performance and Stability Characteristics of Aircrafts-A Comprehensive Review
}

Praneeth HR Mr

Lovely professional University,Phagwara,Punjab,India, pranith1923@gmail.com

Amit Kumar Thakur Dr

Lovely Professional University,Phagwara,Punjab,India, amitthakur3177@gmail.com

Follow this and additional works at: https://commons.erau.edu/ijaaa

Part of the Aerodynamics and Fluid Mechanics Commons

\section{Scholarly Commons Citation}

HR, P., \& Thakur, A. K. (2020). The Detrimental Effect of Rainfall on Performance and Stability Characteristics of Aircrafts-A Comprehensive Review. International Journal of Aviation, Aeronautics, and Aerospace, 7(4). https://doi.org/10.15394/ijaaa.2020.1533

This Literature Review is brought to you for free and open access by the Journals at Scholarly Commons. It has been accepted for inclusion in International Journal of Aviation, Aeronautics, and Aerospace by an authorized administrator of Scholarly Commons. For more information, please contact commons@erau.edu. 
The Detrimental Effect of Rainfall on Performance and Stability Characteristics of Aircrafts-A Comprehensive Review

Cover Page Footnote

Thank you 


\section{Introduction}

The environmental conditions such as Rainfall, wind shear at stunted altitude, rainstorm, turbulent atmosphere, frost, hail, lightning, the amassment of ice have affected the flights year after year. Aircrafts face difficulties in landing and takeoff during heavy rainfall conditions. Several incidents that included overshooting of the runway by aircraft were reported at Mangalore, Mumbai, Kozhikode, and Surat during inclement weather conditions of rainfall. The continent of Europe is predicted to receive more precipitation in the north part of the continent in comparison to the south. There would be more precipitation of rainfall and snow which would cause further disruption in flights. Bad weather accounted for $21 \%$ of total aviation accidents in India during 1992-2008 as per the survey (Jenamani, R. K, \& Kuma, A, 2013) conducted related to rain associated aviation accidents.

The modern world is compact. i.e. any commodities, goods, services, and people can reach any place in the world in a blink of an eye. Air transport plays a major role in being a commuting medium for such a hectic and speedy transport system. As per the Bureau of Transport statistics, (2018) the air traffic sector has experienced a delay 22\% delay from 2004-2017. The pernicious weather conditions of rain and snowfall cause an added delay of 10 to 23 minutes in flight departure time (Borsky, S et.al, 2019).

The review study carried out focuses on rain research techniques, mathematical models considered to develop rain-induced airflow over the airfoil, and detrimental effects of rain on aerodynamics and stability characteristics.

\section{Rain research techniques}

The numerous researches on the effect of rainfall on aircraft aerodynamics carried out until now are done analytically, experimentally and now with the advancement in the computers, analysis software numerical simulation has also 
gained importance. The experimental part involves testing the full scale and scale model flight testing.

\section{Analytical investigation on the effect of rainfall on aircraft}

The analytical study on the effect of rainfall on aircraft is based on experimental data and empirical formulas. The model formulated in the analytical study involves assumptions like raindrop striking the airfoil brings about the loss in momentum of the airfoil. The evaluation of the change in momentum is made by considering the collision of raindrops with airfoil as to be inelastic as suggested by Haines, P. and Luers, J. (1983). The droplets impinging onto the airfoil at an acute angle results in a lesser momentum loss when compared to droplets striking at a reflective angle greater than $90^{\circ}$. Also, it should be noted that that for an elastic collision between the droplet and airfoil surface the impact force is larger when compared to inelastic collisions. This change in momentum gives rise to a change in velocity. The raindrop's vertical velocity component imparts downward momentum to aircraft due to which it sinks. The aircraft loses momentum as splashed back droplets are accelerated to aircraft's velocity, all this abovementioned phenomenon is related to rain droplets horizontal component of velocity.

Another intriguing assumption is the calculation of the thickness of water film due to the accumulation of water droplets on the airfoil. A model considered by Haines and Luers is bereft of pressure gradient, gravity and other forces are unrealistic, leading to malicious results regarding water film thickness. The study on two-phase boundary layers conducted by Henry, R. et.al (1987) proved that neglecting the assumptions of shear stress effects at wall and interface yields fake results.

Bilanin and Hsu, Y.K. (1989) studied the effect of rainfall on aircraft aerodynamics, while the former considered the ejecta layer thickness was constant 
$\mathrm{Hu}$ had a contrasting assumption that the eject thickness varied. FW factor technique was utilized by Wan, T. et, al (2006) in their studies for evaluating the performance of aircraft in adverse weather conditions.

\section{Experimental Investigation}

Full-Scale flight testing in naturally occurring adverse conditions such as heavy rainfall, gusts, wind shear, ice accretion is one of the complex test methods to evaluate flight performance. All these weather conditions are varying, uncontrollable, and can contribute to random errors in testing. There are only a few pieces of literature available that give glimpses on the different artificial techniques available to emulate the adverse weather conditions of rainfall to illustrate the capability of the performance evaluation in aircraft (Adams K, 1983; Hermanspann, F. 1996).

Small Scaled Testing acts as a fill-in technique to overcome techniques of full-scale flight testing as it involves testing a small scaled model of the aircraft or its components such as wing or fuselage. The three predominant types of experimental setup under this category are a small-scale model of wing mounted on a counterbalance beam of a single drop rotating arm setup (Belanin et.al, 1989; Feo, A, 1987), a wind tunnel of smaller scale, (Dunham, JR, R1986 \& Dunham Jr, R.E 1987), and an experimental track setup of a larger scale (Taylor, J. et.al, 1988; Bezos, G. et.al, 1989).

\section{Numerical Technique}

The advances in computational techniques using supercomputers of the modern world have made most researchers opt for Computational Fluid Dynamics as the most common approach to solve fluid flow problems. Lagrangian particle tracking method and Euler's two-phase flow method are the most widely used simulation techniques for airflow influenced by rainfall (Durst, F et.al, 1984; 
Decker, R et.al, 1988). As per Euler's method droplets present in the flow, the field is treated as to be quasi liquid infused in the gas phase. Euler's conservation equation for all the phases is solved, by considering the trade-off mass, momentum, and energy at the interphase level. In the former method, Euler's conservation equation of gas-phase is solved initially and Newton's second law is employed later to track and simulate the droplet trajectory as they are introduced into the flow field by the Lagrangian approach. A study of flow field influenced by rainfall is analyzed to track the trajectory of droplets via a one-way or two-way coupled model. The one-way coupling of models presumes that the continuum gas-phase disturbs the movement of discrete water droplets in the flow field. (Valentine, J.R et.al. 1995), while a two-way coupled model considers the transfer of mass, momentum, and energy between the discrete and continuous phases (Valentine, J.R et.al. 1995) due to drag forces acting at interphase. The momentum balance in the continuous phase during successive computation of the flow field is maintained by the transfer of momentum between the continuous to a discrete phase which is considered as to be momentum source/sink. The above techniques are developed in a two-way Lagrange model in a form of iterative and non-iterative schemes. As per the later one, the two phases are taken separately and iterated until they arrive at the steady-state (Crowe, C. T et.al 1977). For the non-iterative approach, both the phases are computed simultaneously (Dukowicz, J.K, 1980).

\section{Mathematical Model to track flow trajectories}

Raindrops are most commonly considered to be spherically barring a few larger droplets for which empirical correlations of non-sphericity are defined. The forces affecting the droplet motion are Drag force, gravitational force, the force due to buoyancy, virtual mass, thermophoretic force, Brownian force, and Saffman's lift force. Equating the forces acting over the raindrop with the inertia helps in finding 
the trail of droplets in the flow field. For sake of simplicity, many presumptions like no collision between the droplets, coalescence of droplets, absence of turbulence effects of the airflow, and buoyancy forces (Haines, P et.al, 1983; Gent, R.W. 2000) were drafted into equations defining droplet trajectory for rainfall condition.

For a spherical droplet coefficient of drag is given by

$C_{D}=\mathrm{K}_{1}+\frac{K_{2}}{R e}+\frac{K_{3}}{R e^{2}}$ is taken from (Morsi S, 1972)

or from [Gent , R. W. 1984\&2000]

$C_{D}=\frac{24}{R e}\left(1+0.197 \mathrm{Re}^{0.63}+0.00026 \mathrm{Re}^{1.38}\right)$

In the above equations $\mathrm{K}_{1}, \mathrm{~K}_{2}, \mathrm{~K}_{3}$ represent constants for Relative Reynolds number for smooth spherical droplets. (Wu, Z. et.al, 2015). For larger Reynolds number the above equation doesn't hold good as the droplets undergo deformation and lose their spherical shape. Hence a better estimation of $C_{D}$ is given by (Wierzba, A.1990; Feo, A. et.al, 2011) as

$C_{D}=\frac{24}{R e}\left(0.00001699 \mathrm{Re}^{1.92}\right), \operatorname{Re}>3500$

Or from (Valentine, J.R et.al. 1995; Wallis, G.B 1969)

as $C_{D}=\max \left\{0.44, \frac{24}{R e}\left(1+0.15 \mathrm{Re}^{0.687}\right)\right.$

In presence of turbulence, the raindrop particles get dispersed in the continuous phase. The prognosis of dispersed particles is generated using integral time scale $\mathrm{T}$, by considering the turbulent motion along the path of raindrop motion ds. It is given as to be

$T=\int_{0}^{\infty} \frac{u_{p}^{\prime}(t) u_{p}^{\prime}(t+s)}{u_{p}^{\prime 2}(t)}$ from (Wu, Z. et. al, 2015) 


\section{Analysis of rainfall on aircraft aerodynamics}

The following section discusses various case studies on the effect of rainfall on aircraft aerodynamics which picturises rain-induced aerodynamic penalties.

Fatahian.H.et.al (2020) conducted a numerical study to compare the performance of single-element airfoil and slatted airfoil for rainfall and dry conditions. The formation of water film over the surface of the airfoil was simulated using two-way momentum coupled Euler Lagrangian approach. In presence of rain, the lift coefficient decreased by $10 \%$, and drag increased by 60 $\%$ at a lower AOA of $2^{0}$ as seen from Figures $1 \mathrm{a}$ and $1 \mathrm{~b}$ respectively. The addition of slats improvised the aerodynamic characteristics at a higher angle of attack and does escalate the stall angle for both rain and dry conditions. The stall angle increased from $13^{0}$ to $22^{0}$ for a dry day and increased from $16^{0}$ to $24^{0}$ on a rainy day as shown in Figure1a below when a slat is added to the airfoil. At lower AOA water accumulates on the airfoil surface generating water film which leads to degradation in airfoil characteristics are seen as in the case of the L/D ratio. The maximum degradation in L/D occurs at AOA $2^{0}$ which is about $56 \%$. The slatted airfoil exhibits higher values of L/D ration at higher AOA as shown in Figure2 below. The degradation caused by rain on an airfoil is more significant in comparison to the aerodynamic performance caused by the addition of slat for a dry day condition. The above statement could be visualized from Figure 2 which exhibits that at AOA 12 wherein maximum $\mathrm{L} / \mathrm{D}$ ratio is attained, for the case of a rainy day the slatted airfoil achieves maximum L/D of 9.88 in comparison to a dry day when it attains a maximum L/D ratio of 14.09. For a single element airfoil, it could be noticed that for a rainy day the maximum L/D is 9.27 in comparison to a 10.36 the maximum L/D attained on a dry day. 


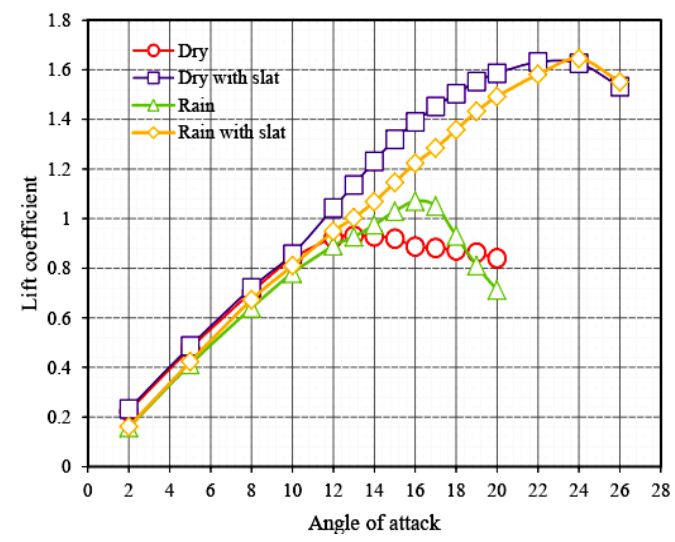

Figure 1a:The variation of $\mathrm{C}_{\mathrm{L}}$ for NACA 0012 airfoil and NACA 0012 airfoil with slats in dry and rainfall condition, Fatahian.H.et.al (2020).

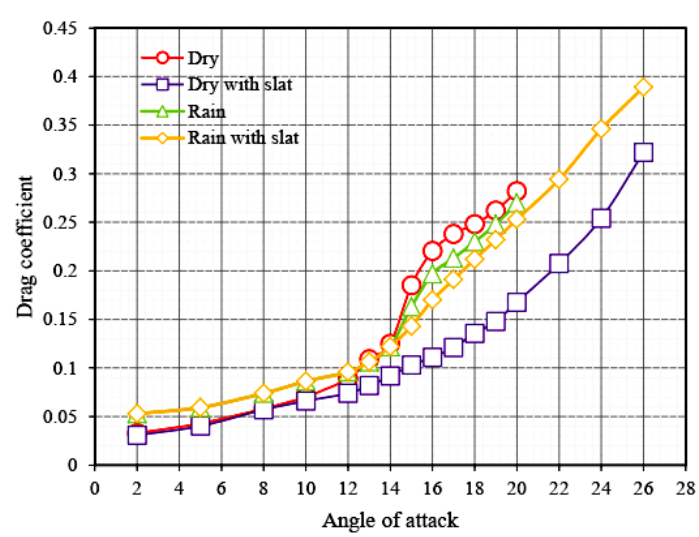

Figure $1 b$ The variation of $\mathrm{C}_{\mathrm{L}}$ and $\mathrm{C}_{\mathrm{D}}$ for NACA 0012 airfoil and NACA 0012 airfoil with slats in dry and rainfall condition, Fatahian.H.et.al (2020).

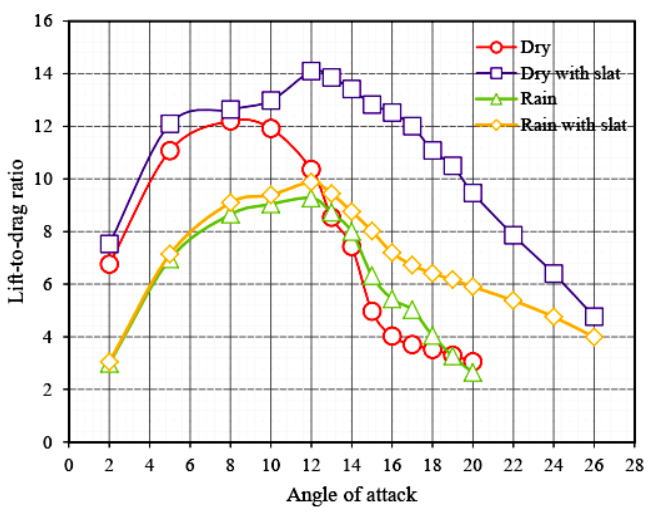

Figure 2. The variation of L/D for NACA 0012 airfoil and NACA 0012 airfoil with slats in dry and rainfall conditions, (Hossein Fatahian et.al, 2020).

The raindrops that splashback after impinging onto the airfoil surface slows down the boundary layer at the leading edge, but the boundary layer overcomes this deceleration downstream. The disparity in the velocity profile of 
the boundary layer is plotted along the chordwise direction at the intervals of $25 \%, 50 \%, 75 \%$, and $95 \%$ of chord lengths respectively. The boundary layer is laminar at $25 \%$ of chord length whereas at $75 \%$ of chord length the boundary layer profile is turbulent resulting in increased thickness. Consequential improvements are found in the shape of velocity profiles of the boundary layer at $75 \%$ chord length for a NACA 0012 aerofoil with slats in case of the wet and dry day as it overcomes the instable flow of the single element airfoil as shown in Figure 3 and 4.

The inclusion of slat causes significant changes in the shape of the velocity profiles at 0.75 chord length for a slatted airfoil on a dry and a rainy day by overcoming the instable flow of the single element airfoil as shown in Figure 3and4. The above-mentioned change results in improved aerodynamic performance and delays the onset of stall.

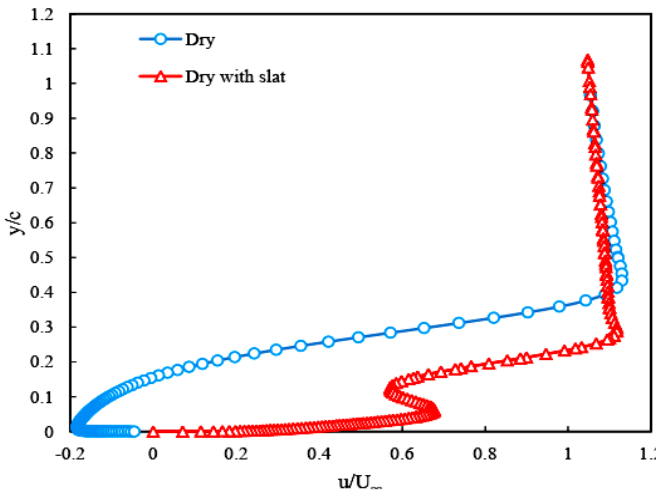

Figure 3. Velocity profile of boundary layer for NACA 0012 airfoil v/s NACA 0012 slatted airfoil at $75 \%$ chord length for $20^{\circ}$ AOA on a dry day, (Fatahian.H.et.al 2020).

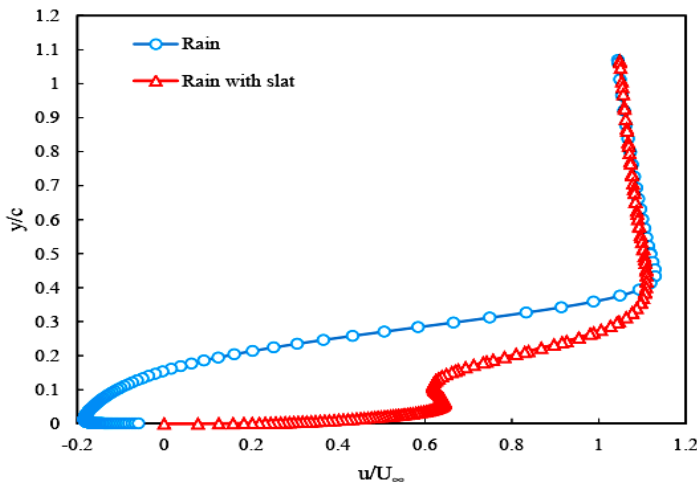

Figure 4. Velocity profile of boundary layer for NACA 0012 airfoil v/s NACA 0012 slatted airfoil at $75 \%$ chord length for $20^{\circ}$ AOA on a rainy day, (Fatahian.H.et.al 2020). 
The addition of slat decreased the concentration of mass of droplets on the main element of the airfoil at AOA of $2^{0}$ as well as $20^{\circ}$ as most of the droplets impinge onto leading edge slats and break into smaller droplets. Thus, the addition of slat results in a decrease of maximum mass of water film mass present from 18 gms to 2.5 gms at $2^{\circ} \mathrm{AOA}$ and from 15 grams to 1 gram at $20^{\circ} \mathrm{AOA}$ as shown in Figure5 and 6 respectively. The addition of slat also results in droplets of smaller size adhere to the main element of the airfoil as shown in Figure 7 (Hossein Fatahian et.al, 2020). The above-mentioned improve aerodynamic characteristics, increasing $\mathrm{C}_{\mathrm{l}}, \mathrm{L} / \mathrm{D}$ ratio, and delay of onset of stall.

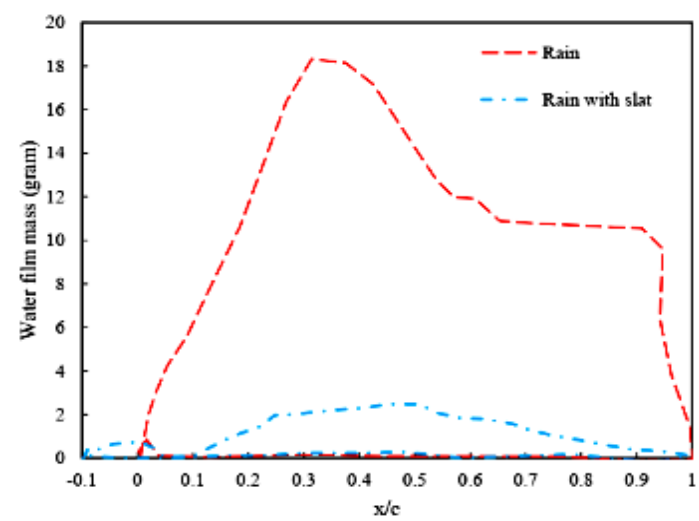

Figure 5. The mass of water film distributed along the chord length at $2^{\circ} \mathrm{AOA}$ for a NACA 0012 aerofoil v/s NACA 0012 aerofoil with slats, (Fatahian.H.et.al 2020)

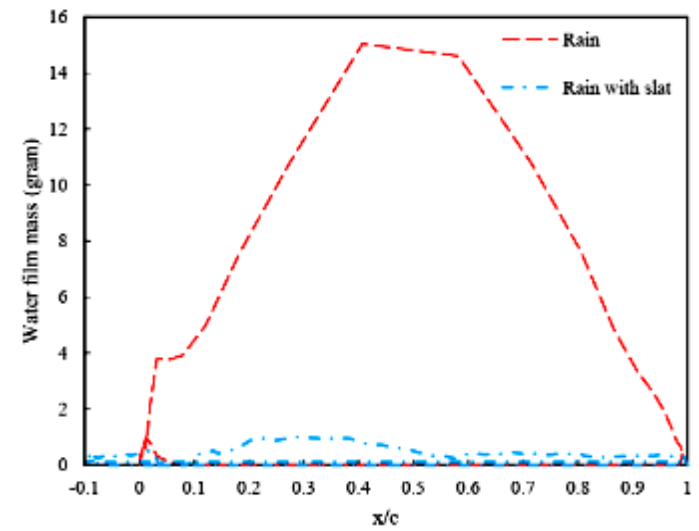


Figure6. The mass of water film distributed along the chord length at $20^{\circ} \mathrm{AOA}$ for a NACA 0012 aerofoil v/s NACA 0012 aerofoil with slats, (Fatahian.H.et.al 2020)

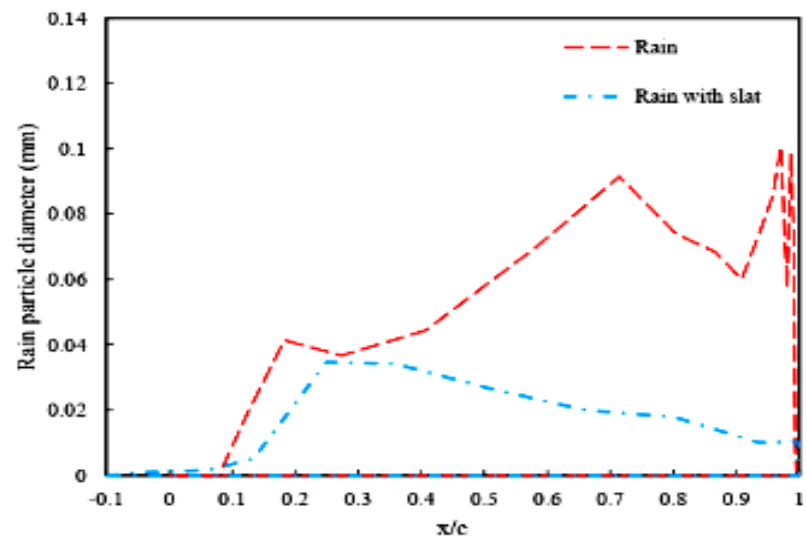

Figure 7. Comparison of Droplet size on single element airfoil v/s slatted airfoil at $20^{0} \mathrm{AOA}$ in a rainfall condition, (Fatahian.H.et.al, 2020)

Wu, Z. et.al (2018) estimated the dynamic derivatives of the DLR-F12 full transport category aircraft for dry and wet conditions. The DPM was employed to simulate the wet conditions and the dynamic meshing method was employed to implement unsteady frequency oscillations for estimating dynamic derivatives. The values of natural characteristics of rainfall considered for the evaluation of dynamic derivatives are as LWC of $30 \mathrm{~g} / \mathrm{m}^{3}$, raindrop diameter of $1 \mathrm{~mm}$, and terminal velocity of $4 \mathrm{~mm} / \mathrm{s}$. The static $\mathrm{C}_{\mathrm{L}}$ and $\mathrm{C}_{\mathrm{m}}$ showed a linear relationship with respect to $\alpha$ in the range of AOA considered as shown in Figures 8 and 9 below. The slope of static lift coefficient $\left(\mathrm{C}_{\mathrm{L} \alpha}\right)$ and moment coefficient $\left(\mathrm{C}_{\mathrm{m} \alpha}\right)$ reduced by $15 \%$ and $18 \%$ respectively for a wet condition which was similar to the study done by (Ismail, M. et.al, 2012). Rainfall also contributed towards the decrease of static lift and moment coefficients by $33 \%$ and $25 \%$ respectively. This abasement of the above-mentioned aerodynamic characteristics caused a decrease 
in lift thus aircraft engines have to produce more power to overcome the loss of lift to balance the weight force.

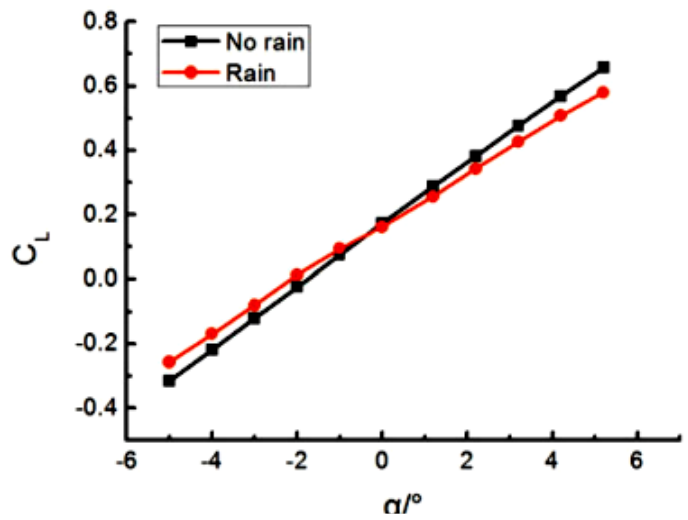

Figure 8. Variation of static $\mathrm{C}_{\mathrm{L}} \mathrm{v} / \mathrm{s}$ AOA for dry and wet condition, (Wu, Z. et.al.2018)

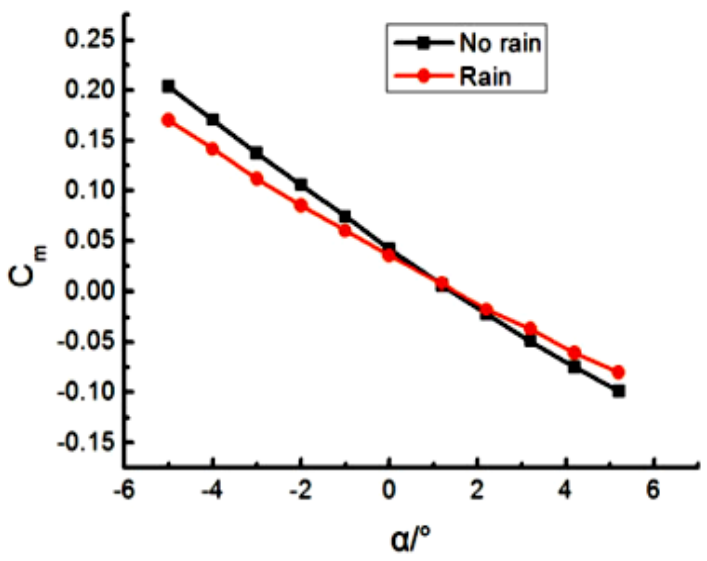

Figure 9. Variation of static $\mathrm{Cm}$ v/s AOA for dry and wet condition, (Wu, Z. et.al.2018)

The dynamic derivatives also degraded in the same manner as was in the case of static ones in presence of rainfall. The degradation of the dynamic derivatives differed from one another as seen from Table 2 . The negative sign in 
the table signifies the degradation of derivatives in presence of rainfall when compared with a dry day. $C_{L \dot{\alpha}}$ and $C_{m \dot{\alpha}}$ the two unsteady derivatives show to exhibit considerable degradation above $30 \%$ in rainfall conditions when compared with a dry day. The study showcases that $\alpha$ and q the representatives of the shortperiod mode of flight depend on $C_{L \dot{\alpha}}$ and $C_{m \dot{\alpha}}$ thus the short period mode flight performance may be affected by the rainfall conditions. The results match with the previous study by $\mathrm{Wu}$, Z.et.al (2015)

\begin{tabular}{|c|c|c|c|}
\hline \multicolumn{4}{|c|}{$\begin{array}{l}\text { Table 2: Comparison of Dynamic Derivatives on a Dry v/s Wet day, } \\
(\text { Wu, Z. et.al 2018) }\end{array}$} \\
\hline Parameters & Dry & Wet & $\Delta=($ Wet-Dry $) /$ Dry x $100 \%$ \\
\hline $\mathrm{C}_{\mathrm{L} \alpha}$ & 5.49 & 4.68 & $-14.75 \%$ \\
\hline $\mathrm{C}_{\mathrm{Lq}}$ & 10.62 & 9.87 & $-7.06 \%$ \\
\hline $\mathrm{C}_{\mathrm{Lq}}+C_{L \dot{\alpha}}$ & 7.48 & 7.80 & $4.28 \%$ \\
\hline$C_{L \dot{\alpha}}$ & -3.14 & -2.07 & $-34.08 \%$ \\
\hline $\mathrm{C}_{\mathrm{m} \alpha}$ & -1.71 & -1.40 & $-18.13 \%$ \\
\hline $\mathrm{Cm}_{\mathrm{q}}$ & -17.64 & -15.96 & $-9.52 \%$ \\
\hline $\mathrm{Cm}_{\mathrm{q}+} C_{m \dot{\alpha}}$ & -19.93 & -17.55 & $-6.92 \%$ \\
\hline$C_{m \dot{\alpha}}$ & -2.29 & -1.59 & $-30.57 \%$ \\
\hline
\end{tabular}

Ismail, M. and Cao et.al (2012\& 2014) employed a two-phase flow approach to analyze aerodynamic efficiency of the 2D airfoil of NACA 0012 configuration and 3D rectangular wing having NACA 0012 configuration in wet conditions. DPM employed replicates the distribution of rain droplets in the uninterrupted air medium. The cruise configuration of a 2D airfoil with NACA 0012 configuration exposed to flow conditions of Reynolds's no $3.1 \times 10^{5}$ and LWC of $39 \mathrm{~g} / \mathrm{m}^{3}$ exhibited adverse characteristics of decremental lift and incremental drag. The L/D ratio degraded to a maximum of $25 \%$ in comparison to a dry 
condition at AOA ranging from $6^{0}$ to $10^{0}$. During rainfall, the symmetric NACA 0012airfoil exhibited a decrease in L/D ratio by $20 \%$ in comparison to a dry day at AOA $6^{0}$ to $12^{0}$ during the take-off and landing phase of aircraft for flow conditions of Reynolds No 1.7 x $10^{6}$ and LWC of $22 \mathrm{~g} / \mathrm{m}^{3}$.

The numerical analysis of flow over a 3d NACA 0012 rectangular wing in presence of rainfall exhibited the abasement of the L/d ratio by $10 \%$ for flow conditions of Reynolds No $7 \times 10^{6}$ and LWC of $32 \mathrm{~g} / \mathrm{m}^{3}$. Figures $10 \mathrm{a}, \mathrm{b}, \mathrm{c}$ and d exhibited spanwise pressure and velocity distribution for LWC of $0 \mathrm{~g} / \mathrm{m}^{3}$ and 32 $\mathrm{g} / \mathrm{m}^{3}$. Narrowing of difference in pressure values at the leading edge of both top and bottom airfoil surfaces in presence of rainfall. This results in decreases in lift and degradation of the $\mathrm{L} / \mathrm{D}$ ratio.

a

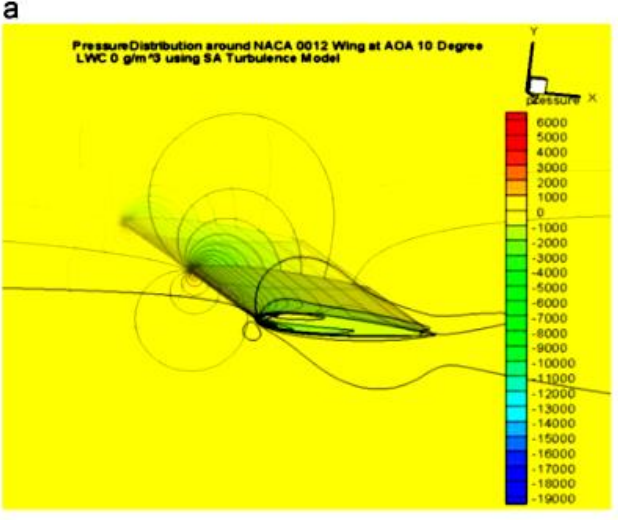

b

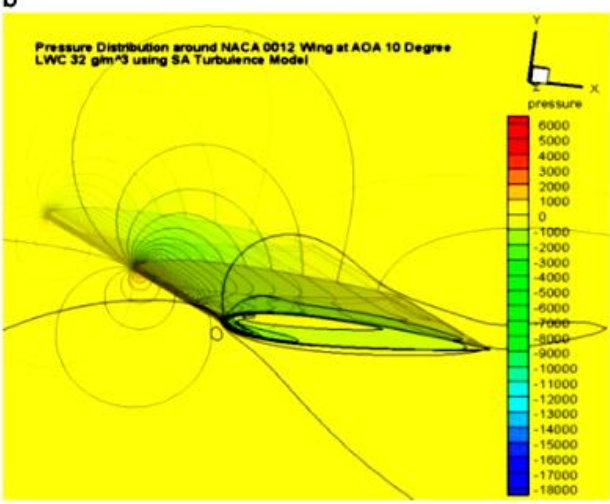

Figure 10a\& Figure 10b. Pressure distribution for a cruise configuration of NACA 0012 airfoil in a wet and dry scenario (Ismail and Cao et.al, 2014) 
c

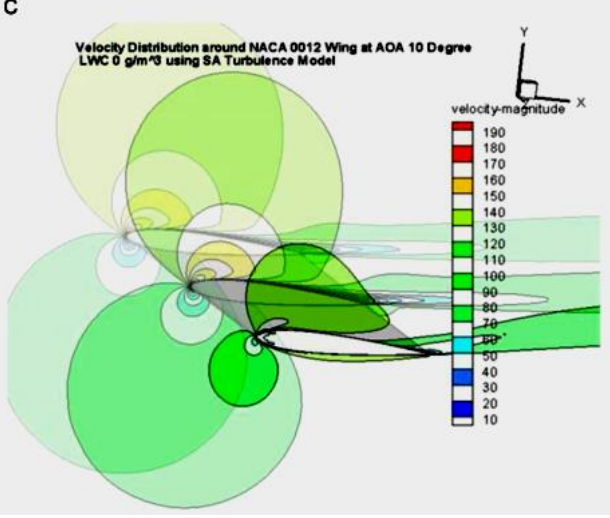

d

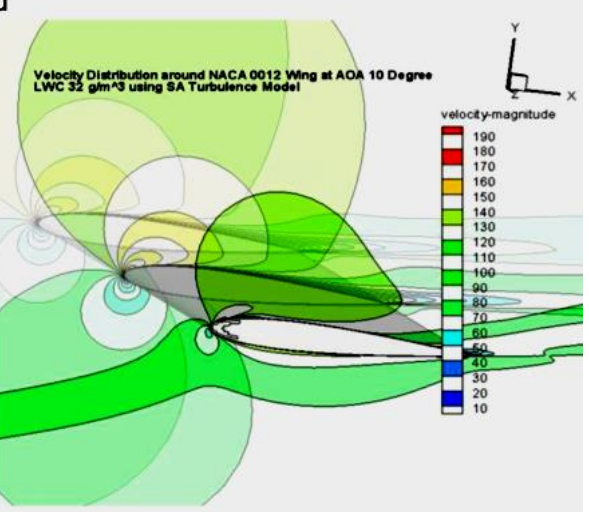

Figure 10c\& Figure 10d. Velocity distribution for a cruise configuration of NACA 0012 airfoil in a wet and dry scenario (Ismail, M. and Cao et.al, 2014)

Various configurations of airfoils such as NACA 4412, NACA 0012, NACA 64-210, Blended wing aircraft, and helicopter rotor blades are investigated numerically by two-phase flow approach for their aerodynamic efficiency during adverse weather conditions of rainfall. Loss of lift and increment in makes heavy rainfall induce grave aerodynamic retributions on components under study. The detrimental rain influence on the component increases with an increase in LWC and intensity of rainfall.

Yeom, G.S. et.al [2012] computed the deterioration of transonic flow characteristics over NACA 0012 in presence of rainfall. The flow field was analyzed using a two-fluid model solved using WAF- HIL technique, which included various facets of association between water droplets and gas such as transfer of heat, change in phase, breaking of droplets but excluded interaction between the droplets themselves or either interaction between the wall and droplet. The effect of parameters such as the initial volume of raindrop and size of droplets on the $\mathrm{C}_{\mathrm{p}}$ of the wall and scaled aerodynamic coefficients of the airfoil along chordwise direction was tested and summarised as shown in Figures11 to 13 
The shock exists in the case of only gas flow near the trailing edge when the droplet volume fraction is $0.1 \%$ as shown in Figure 11 below, as the droplet volume fraction increases the wall pressure increases in front of shock but decreases behind it. The shock fades of for higher droplet volume fraction (Yeom et.al, 2012).
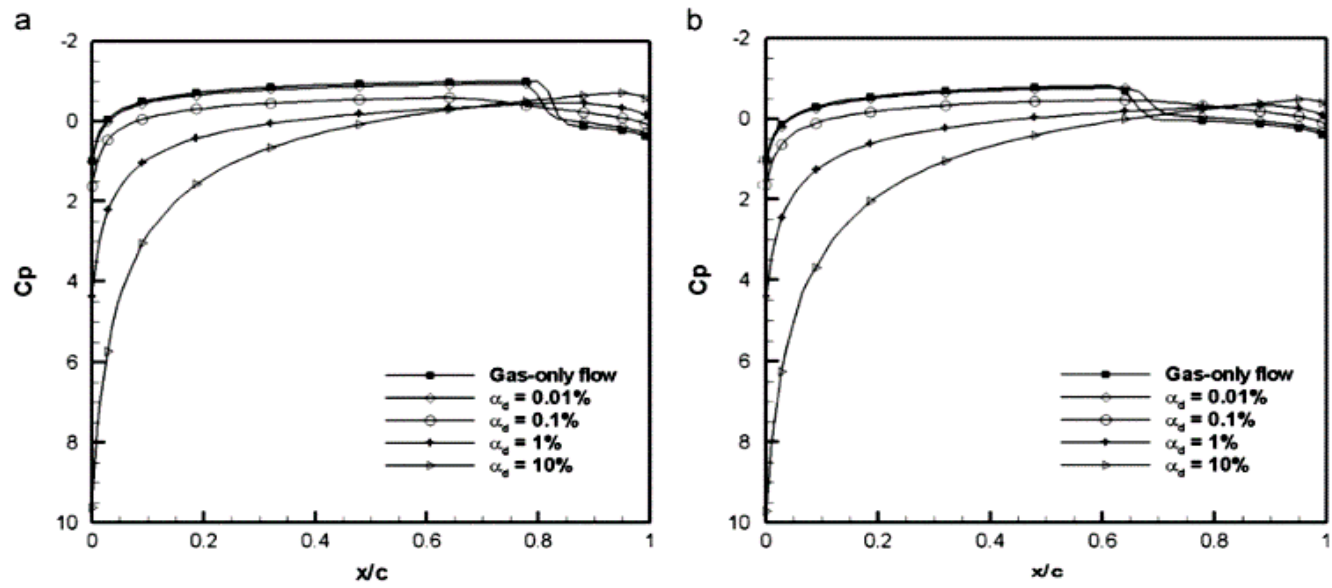

Figure 11a \& Figure11b. Wall pressure co-efficient on the higher and lower surface of the airfoil at $1^{\circ}$ AOA respectively. The droplet initial dia is $100 \mu \mathrm{m}$. (Yeom et.al, 2012)

The $C_{L}$ value increases and $C_{D}$ decreases with an increase in AOA. But in contrast, the slopes of lift coefficient decrease, and the slopes of the coefficient of drag decreases in the presence of higher droplet volume fraction which indicates abasement of aerodynamic properties for high density of water droplets as shown in Figure 12. 
a

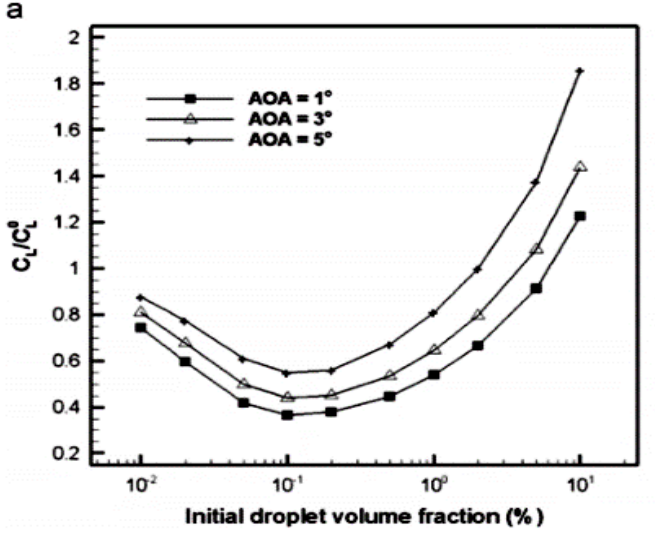

b

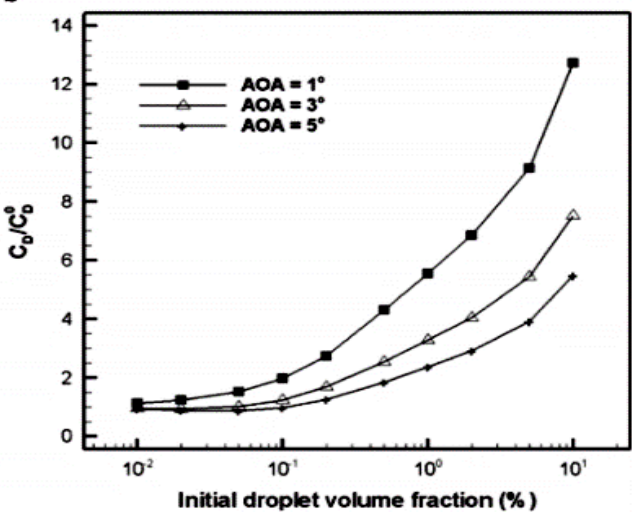

Figure $12 a$ \& Figure $12 b$. Scaled $\mathrm{C}_{\mathrm{L}}$ and $\mathrm{C}_{\mathrm{D}} \mathrm{v} / \mathrm{s}$ initial volume fraction of droplet respectively. The initial dia of the droplet is $100 \mu \mathrm{m}$. (Yeomet. al, 2012)

It is also found from the study that droplets of smaller size impose greater aerodynamic degradations in wet conditions than the larger droplets having greater volume fraction as seen from Figure 13.
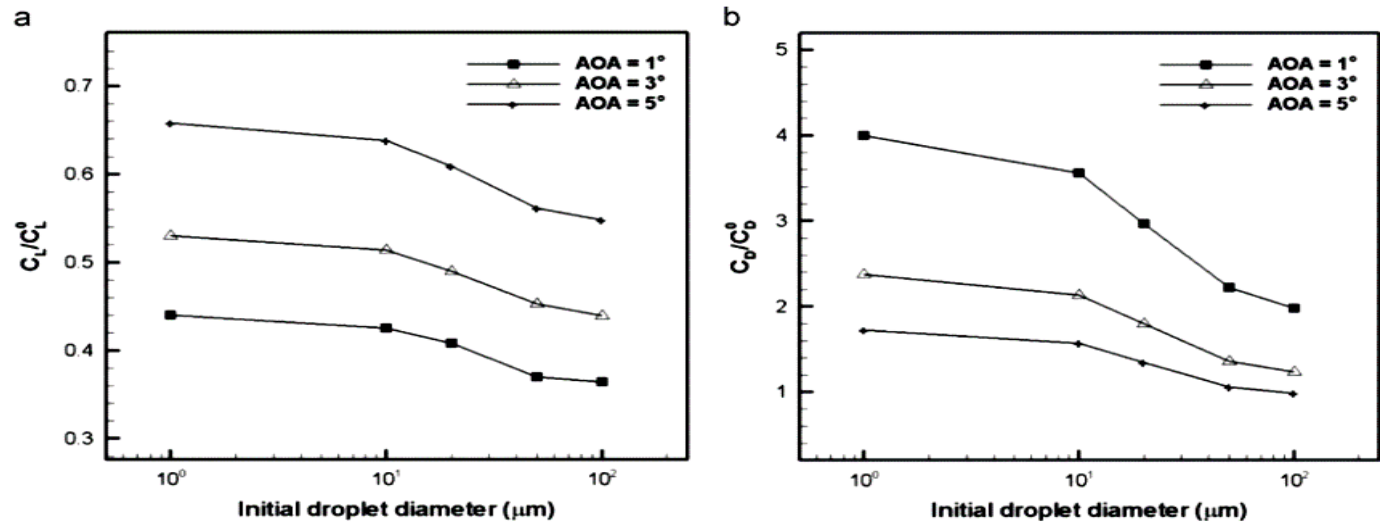

Figure $13 a \&$ Figure $13 b$. Scaled $\mathrm{C}_{\mathrm{L}}$ and $\mathrm{C}_{\mathrm{D}}$ v/s initial volume fraction of droplet[86]. The initial volume fraction is set to $0.1 \%$ for the droplet. (Yeom et.al, 2012)

$\mathrm{Wu}, \mathrm{Z}$. et.al(2018) examined the aerodynamic performance, lateral and directional stability aspects of the DHC-6 Twin Otter aircraft during rainfall. An 
Eulerian-Lagrangian stratagem conjoined two-sided momentum transfer is utilized to estimate aerodynamic parameters for wing and tail which contribute towards aircraft stability and control. Linear fitting of aerodynamic data is utilized to arrive at static derivatives and dynamic derivatives are estimated by strip theory derived formulae containing aerodynamic data. The results obtained in the study indicate that the derivatives viz $\left(\mathrm{C}_{w}\right)_{\alpha}, \quad\left(\mathrm{C}_{\mathrm{zh}}\right)_{\alpha}, \quad\left(\mathrm{C}_{\mathrm{lw}}\right)_{\delta \mathrm{a}},\left(\mathrm{C}_{\mathrm{lw}}\right)_{\beta}$ of the thirteen lateral/directional aerodynamic derivatives are more influenced due to rain intensity. The aerodynamic derivative $\left(\mathrm{C}_{\mathrm{lw}}\right) \delta \mathrm{a}$ has the largest degradation of $42 \%$ in comparison to a dry day condition while $\left(\mathrm{C}_{\mathrm{zh}) \alpha}\right.$ has the least degradation of $14 \%$ for a scenario of heavy rainfall characterized by LWC of $45 \mathrm{~g} / \mathrm{m}^{3}$. All the remaining derivatives suffer abasement of about $3 \%$ due to wet conditions.

Rain also has an adverse effect on stability and control aspects of the aircraft as defined by various occurrences like the Dutch roll mode dampening ratio increased by $15 \%, \mathrm{t}_{1 / 2}$ increased by $8 \%$ for roll and spiral modes, reduction in natural frequency by $7 \%$. The effectiveness of rudder and aileron reduces as the steady-state response of sideslip angle, yawing velocity, and rolling angle during rainfall condition.

Wan, T. et, al (2010) investigated the effect of rainfall on blended wing body aircraft. A rainy condition is simulated over the $3 \mathrm{~d}$ blended wing using a two-phase flow approach. The numerical results obtained for estimation of $\mathrm{C}_{\mathrm{L}}$ and $\mathrm{C}_{\mathrm{D}}$ a $3 \mathrm{~d}$ wing is compared with experimental studies carried by Bezo's as shown in Figures 14 and 15. The difference in lift curve slope and value of $\mathrm{C}_{\mathrm{L}}$ at $0^{\circ} \mathrm{AOA}$ is due to dissimilarities in geometry between the 2-D airfoil and 3D BWB. In the case of 3D BWB, most of the part of the wing is exposed to wet conditions thus it has much higher skin frictional drag in comparison to the $2 \mathrm{~d}$ airfoil considered in the experiment by Bezo’s. 


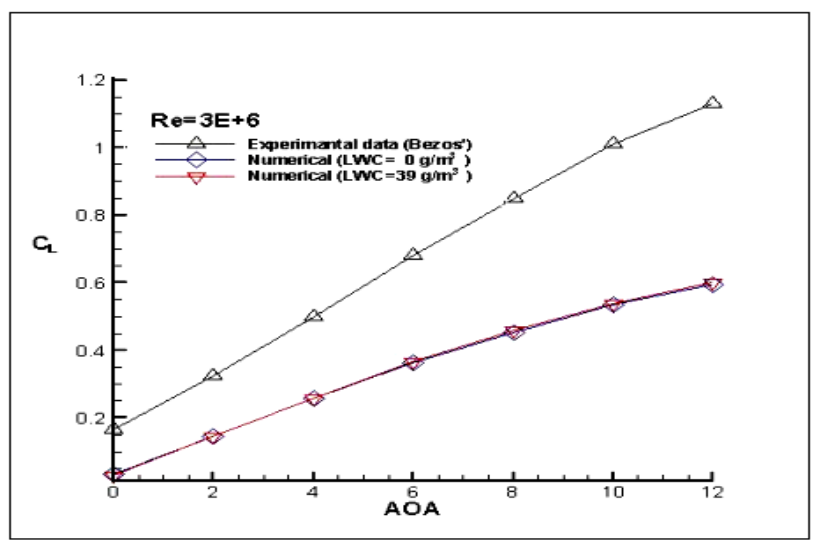

Figure 14. Comparison of $\mathrm{C}_{\mathrm{L}}$ v/s AOA for BWB aircraft with experimental data from Bezo’s experiment. (Wan, T. et, al, 2010)

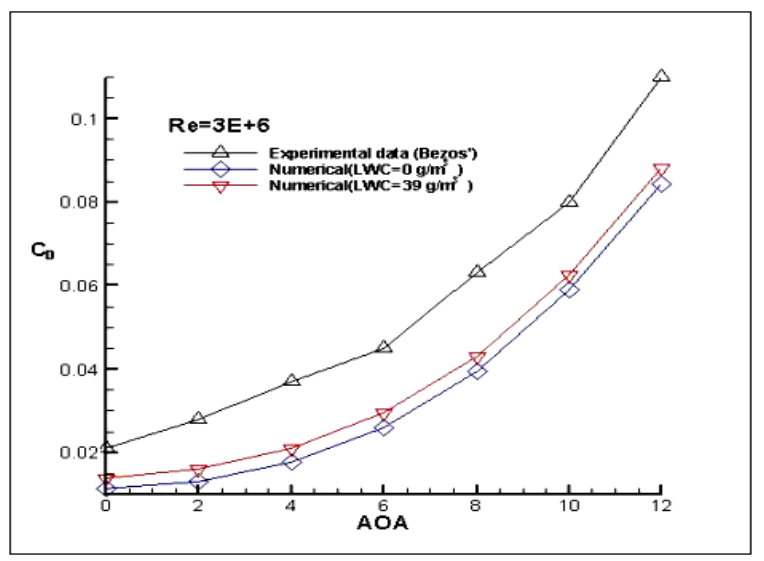

Figure 15. Comparison of $\mathrm{C}_{\mathrm{D}} \mathrm{v} / \mathrm{s} \mathrm{AOA}$ for $\mathrm{BWB}$ aircraft with experimental data from Bezo’s experiment. (Wan, T. et, al, 2010)

The lift in the BWB aircraft is influenced greatly by wingtip vortices and cross-flow in comparison to the effect of rainfall, thus $C_{L}$ varies vary slightly during take-off or landing for different rainfall rates as shown in Figure 16 which suits the practical scenario. At higher Reynolds, no greater mixing of air and water droplets takes place resulting in the formation of small water films over the wing surface which results in a minimal increase of drag at higher AOA as 
depicted in Figure 17. Thus, at higher AOA the BWB lift or degradation becomes less. The impact of raindrop degrades the aerodynamic properties of a flat $2 \mathrm{~d}$ airfoil severely in comparison to BWB. The maximum degradation of the L/D ratio of $10 \%$ or 1.6 occurs in the case of $\mathrm{BWB}$ at $4^{0} \mathrm{AOA}$ during take-off or landing when the aircraft is exposed to heavy rainfall as shown in Figure 18.

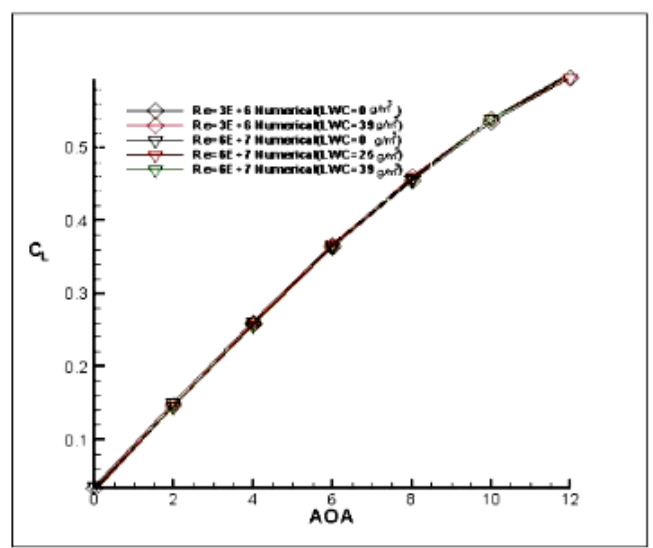

Figure 16. Comparison of $\mathrm{C}_{\mathrm{L}}$ for various rainfall rates,(Wan, T. et, al, 2010).

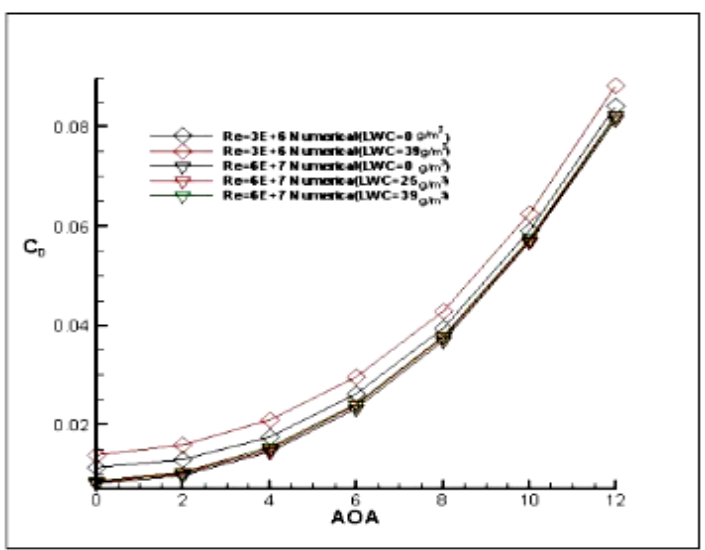

Figure 17. Comparison of $\mathrm{C}_{\mathrm{D}}$ for various rainfall rates, (Wan, T. et, al, 2010). 


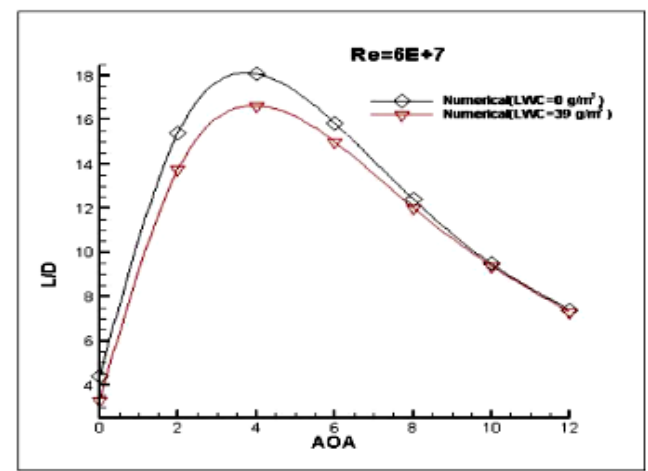

Figure18. Effect of rainfall on the L/D ratio of BWB aircraft, (Wan, T. et, al, 2010).

\section{CONCLUSION}

The paper is an eclectic study on the various rainfall accidents, rain research techniques, and aerodynamic penalties imposed by rainfall on aircraft. The following are some important conclusions:

Rainfall decreases lift, the slope of lift curve, L/D and increases drag of various configuration of an airfoil differently. This degradation of aerodynamic characteristics may lead to serious aircraft accidents. Laminar airfoils face greater aerodynamic degradation in comparison to transport category or symmetric airfoils. It has to be noted that not all the airfoils undergo aerodynamic degradation due to different conditions of rainfall and flight parameters.

Rain can have a negative or positive impact on stall characteristics of an aircraft, in some cases, the rainfall can cause premature stall while in case of some airfoils can achieve enhanced stall performance.

Rainfall eliminates the difference in pressure over upper and lower surfaces of the airfoil at the leading edge of the airfoil which results in a decrease in the lift, L/D, premature flow, and boundary layer separation. 


\section{REFERENCES}

Adams, K. (1983). The air force flight test center palletized airborne water spray system. In 21st Aerospace Sciences Meeting (p. 30).

Adams, K. (1983, November). The Air Force Flight Test Center artificial icing and rain testing capability. In the 2nd Flight Testing Conference (p. 2688).

Airplanes, B. C. (1959). Statistical summary of commercial jet airplane accidents. Worldwide Operations, 2008.

BEITEL, G., \& MATTHEWS, R. (1986). A new rain/ice test capability to simulate flight. In 3rd Flight Testing Conference and Technical Display (p. 9824).

BEZOS, G., DUNHAM, JR, R., GENTRY, JR, G., \& MELSON, JR, W. (1987, January). Wind tunnel test results of heavy rain effects on airfoil performance. In 25th AIAA Aerospace Sciences Meeting (p. 260).

BEZOS, G., CAMBELL, B., \& MELSON, W. (1989, January). The development of a capability for aerodynamic testing of large-scale wing sections in a simulated natural rain environment. In 27th Aerospace Sciences Meeting (p. 762).

Bezos, G. M., \& Campbell, B. A. (1993). Development of a large-scale, outdoor, ground-based test capability for evaluating the effect of rain on airfoil lift.

Borsky, S., \& Unterberger, C. (2019). Bad weather and flight delays: The impact of sudden and slow onset weather events. Economics of transportation, 18, $10-26$. 
BOWER, R. (1986, March). Current wind tunnel capability and planned improvements at the NASA Langley Research Center. In 14th Aerodynamic Testing Conference (p. 727).

Cao, Y., Wu, Z., \& Xu, Z. (2014). Effects of rainfall on aircraft aerodynamics. Progress in Aerospace Sciences, 71, 85-127.

Crowe, C. T., Sharma, M. P., \& Stock, D. E. (1977). The Particle Source in Cell (PSI-CEL) Model for Gas Droplet Flows. J. Fluids Eng, 99(1).

Decker, R., \& Schafer, C. F. (1988). Mixing and demixing processes in multiphase flows with application to propulsion systems.

DUNHAM, JR, R. (1986, September). Potential influences of heavy rain on general aviation airplane performance. In General Aviation Technology Conference (p. 2606).

Dunham Jr, R. E. (1987). The potential influence of rain on airfoil performance

Dukowicz, J. K. (1980). A particle-fluid numerical model for liquid sprays. Journal of computational Physics, 35(2), 229-253.

Durst, F., Miloievic, D., \&Schönung, B. (1984). Eulerian and Lagrangian predictions of particulate two-phase flows: a numerical study. Applied Mathematical Modelling, 8(2), 101-115.

Fatahian, H., Salarian, H., Nimvari, M. E., \& Khaleghinia, J. (2020). CFD simulation of aerodynamic performance and flow separation of single element and slatted airfoils under rain condition. Applied Mathematical Modelling.

Feo, A. (1987). Rotating arms applied to studies of single angular drop impacts. In 25th AIAA Aerospace Sciences Meeting (p. 257).

Feo, A., Vargas, M., \& Sor, S. (2011). Rotating Rig Development for Droplet Deformation/Breakup and Impact Experiments Induced by Aerodynamic 
Surfaces. In SAE 2011 International Conference on Aircraft and Engine Icing and Ground Deicing, SAE International Paper (pp. 38-0087).

Gent, R. W. (1984). Calculation of Water Droplet Trajectories about an Aerofoil in Steady. Two-Dimensional, Compressible Flow, "RAE TR, 84060.

Gent, R. W., Dart, N. P., \& Cansdale, J. T. (2000). Aircraft icing. Philosophical Transactions of the Royal Society of London. Series A: Mathematical, Physical and Engineering Sciences, 358(1776), 2873-2911.

Haines, P., \& Luers, J. (1983). Aerodynamic penalties of heavy rain on landing airplanes. Journal of Aircraft, 20(2), 111-119.

Henry, R., Pasamehmetoglu, P., \& Eno, B. (1987, January). A Von Karman integral approach to a two-phase boundary layer problem. In 25th AIAA Aerospace Sciences Meeting (p. 256).

Hermanspann, F. (1996). Rain effects on natural laminar flow airfoils. In 34th Aerospace Sciences Meeting and Exhibit (p. 899).

Hsu, Y. K. (1989). An analytic study of nonsteady two-phase laminar boundary layer around an airfoil. 1989 NASA-ASEE Summer Faculty Fellowship Program in Aeronautics and Research, 86-88.

Ismail, M., Yihua, C., Ming, Z., \& Bakar, A. (2012). Numerical study of airfoils aerodynamic performance in heavy rain environment. International Journal of Aerospace and Mechanical Engineering, 6(7), 1342-1349.

Ismail, M., Yihua, C., Bakar, A., \& Wu, Z. (2014). Aerodynamic efficiency study of $2 \mathrm{D}$ airfoils and 3D rectangular wing in heavy rain via two-phase flow approach. Proceedings of the Institution of Mechanical Engineers, Part G: Journal of Aerospace Engineering, 228(7), 1141-1155. 
Ismail, M., Wu, Z., Bakar, A., \& Tariq, S. (2015). Aerodynamic characteristics of airfoil cruise landing and high lift configurations in simulated rain environment. Journal of Aerospace Engineering, 28(5), 04014131.

Jenamani, R. K., \& Kumar, A. (2013). Bad weather and aircraft accidents-global vis-à-vis Indian scenario. Current Science, 316-325.

Morsi, S. A. J., \& Alexander, A. J. (1972). An investigation of particle trajectories in two-phase flow systems. Journal of Fluid mechanics, 55(2), 193-208.

TAYLOR, J., MOORE, III, C. A. D. D., CAMPBELL, B., \& MELSON, JR, W. (1988, January). The development of a facility for full-scale testing of airfoil performance in simulated rain. In 26th Aerospace Sciences Meeting (p. 55).

Thompson, B. E., \& Marrochello, M. R. (1999). Rivulet formation in surfacewater flow on an airfoil in rain. AIAA journal, 37(1), 45-49.

Valentine, J. R., \& Decker, R. A. (1995). A Lagrangian-Eulerian scheme for flow around an airfoil in rain. International journal of multiphase flow, 21(4), 639-648.10.1016/0301-9322(95)00007-K

Wallis, G. B. (1969). One-dimensional two-phase flow.

Wan, T., \& Wang, C. M. (2006). A Study of Aircraft performance parameter under adverse weather conditions. In 44th AIAA Aerospace Sciences Meeting and Exhibit (p. 234).

Wan, T., \& Pan, S. P. (2010, September). Aerodynamic efficiency study under the influence of heavy rain via two-phase flow approach. In 27th international congress of the aeronautical sciences (Vol. 2, pp. 1343-1353). 
Wan, T., \& Yang, H. (2010, January). Aerodynamic performance investigation of a modern blended-wing-body aircraft under the influence of heavy rain condition.

Wan, T., \& Song, B. C. (2012). Aerodynamic performance study of a modern blended-wing-body aircraft under severe weather simulation. In Proceedings of the 50th AIAA Aerospace Science Meeting including the New Horizons Forum and Aerospace Exposition.

Wierzba, A. (1990). Deformation and breakup of liquid drops in a gas stream at nearly critical Weber numbers. Experiments in fluids, 9(1-2), 59-64.

Wu, Z., \& Cao, Y. (2015). Numerical simulation of flow over an airfoil in heavy rain via a two-way coupled Eulerian-Lagrangian approach. International Journal of Multiphase Flow, 69, 81-92.

Wu, Z., Cao, Y., \& Ismail, M. (2015). Heavy rain effects on aircraft longitudinal stability and control determined from numerical simulation data. Proceedings of the Institution of Mechanical Engineers, Part G: Journal of Aerospace Engineering, 229(10), 1824-1842.

Wu, Z., Cao, Y., \& Yang, Y. (2018). Direct CFD prediction of dynamic derivatives for a complete transport aircraft in the dry and heavy rain environment. The Aeronautical Journal, 122(1247), 1-20.

Wu, Z., Lv, B., \& Cao, Y. (2018). Heavy rain effects on aircraft lateral/directional stability and control determined from numerical simulation data. Aerospace Science and Technology, 80, 472-481

Yeom, G. S., Chang, K. S., \&Baek, S. W. (2012). Numerical prediction of airfoil characteristics in a transonic droplet-laden air flow. International journal of heat and mass transfer, 55(1-3), 453-469. 